\title{
Degradation study of stevioside using RP-HPLC and ESI-MS/MS
}

\author{
Yohanes Martono a, ${ }^{\text {, }}$, Abdul Rohman ${ }^{\mathrm{b}}$, Sudibyo Martono ${ }^{\mathrm{b}}$, Sugeng Riyanto ${ }^{\mathrm{b}}$ \\ a Chemistry Department, Faculty of Science and Mathematics, Universitas Kristen Satya Wacana Salatiga, Jl Diponegoro 52-60 Salatiga 50711, \\ Central Java, Indonesia \\ ${ }^{b}$ Faculty of Pharmacy, Gadjah Mada University, Yogyakarta 55221, Indonesia
}

*Corresponding author: yohanes.martono@staff.uksw.edu

\section{Article history}

Submitted 20 December 2017

Received 7 March 2018

Accepted 1 April 2018

Published Online 30 April 2018

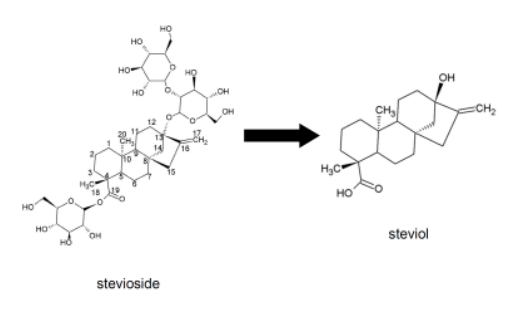

\begin{abstract}
Stevioside is very potential to be an antidiabetic pro-drug. In processing, the active ingredient may be degraded. This research conducted a study of the degradation of stevioside on several stress factors such as acid and base hydrolysis, exposure to UV rays, thermal heating, and oxidation using a reversed phase-high performance liquid chromatography (RP-HPLC). The degradation products were identified using electrospray ionization tandem mass spectrometry (ESI-MS/MS). Hydrolysis of acid-base solution and exposure to UV254 nm rays caused the breakdown of glycoside bonds in the analyte. Stevioside was unstable in dry heating at $105{ }^{\circ} \mathrm{C}$ for 48 hours with degradation of $91 \%$. Stevioside was oxidized by hydrogen peroxide $\left(\mathrm{H}_{2} \mathrm{O}_{2}\right)$ for 48 hours. Based on the ESI-MS/MS analysis, the identified stevioside degradation products were $[\mathrm{M}-\mathrm{H}]^{-}$with the $\mathrm{m} / \mathrm{z}=803$ as stevioside, $[\mathrm{M}-\mathrm{H}]^{-}$with the value of $\mathrm{m} / \mathrm{z}=641$ as steviolbioside, $[\mathrm{M}-\mathrm{H}]^{-}$with the $\mathrm{m} / \mathrm{z}=479$ as steviolmonoside, and $[\mathrm{M}-\mathrm{H}]^{-}$with the $\mathrm{m} / \mathrm{z}=317$ as steviol. Termination of glucose was characterized by fragmentation $[\mathrm{M}-162]^{-}$. Our study provides a basic view of the stability and degradation characteristics of stevioside and demonstrates the formation of degradation products.
\end{abstract}

Keywords: degradation, ESI-MS/MS, HPLC, stevioside

(C) 2018 Penerbit UTM Press. All rights reserved

\section{INTRODUCTION}

Stevioside (Fig. 1) is a dominant diterpene glycoside compound contained in Stevia rebaudiana Bertoni. Stevioside is potentially developed as a candidate for type 2 antidiabetic drugs because it has significant antihyperglycemic bioactivity (Gregersen et al., 2004). Stevioside also has some bioactivities as anticancer (Takasaki et al., 2009), anti-diarrhea (Wang et al., 2014), immunomodulatory (Sehar et al., 2008), and antioxidant (Hajihashemi and Geuns, 2013; Kim et al., 2011). Bioactivity of stevioside as antidiabetic is dose-dependent (Gregersen et al., 2004; Jeppesen et al., 2000; Kujur et al., 2010; Melis and Sainati, 1991).

During the processing of raw materials into products, the analytes may be degraded. The stevioside compound in carbonated beverages is degraded into other compounds that are influenced by environment, temperature, and $\mathrm{pH}$ (Prakash et al., 2012; Wölwer-Rieck et al., 2010). In water, stevioside is stable at heating up to $120{ }^{\circ} \mathrm{C}$ and starts to degrade at heating of more than $140{ }^{\circ} \mathrm{C}$. While stevioside is stable at the range $\mathrm{pH}$ of $2.0-10.0$, it degraded at $\mathrm{pH}$ of 1.00 (Kroyer, 2010). However, stevioside is not degraded and affected by light (Clos et al., 2008). Stevioside is also stable in semi-skim milk products, soy beverages, fermented milk, ice cream, yogurt, biscuits, and jams (Jooken et al., 2012).

The study of the hydrolysis of stevioside standard in acid and base solutions by heating using reflux shows the breaking of glycoside bonds on C-19 atoms and one glycoside bond at C-13 (Chaturvedula and Prakash, 2011). Study of stevioside degradation in acid solution is carried out using liquid chromatography and mass spectrometry to identify its degradation product (Catharino and Santos, 2012; Musa et al., 2014). Dry heating, oxidation, and UV light are also stressing factors that can be applied for forced degradation of a standard compound instability study for biopharmaceuticals product development (Tamizi and Jouyban, 2016). Although studies about stevioside stability in some food and acid-base systems have been investigated, degradation studies of UV light stress factors, dry heating, oxidation and identification of degradation products are still limited. This study will explore the stevioside degradation against acid-base-neutral hydrolysis stressing factors, UV exposure, dry heating, and oxidation.

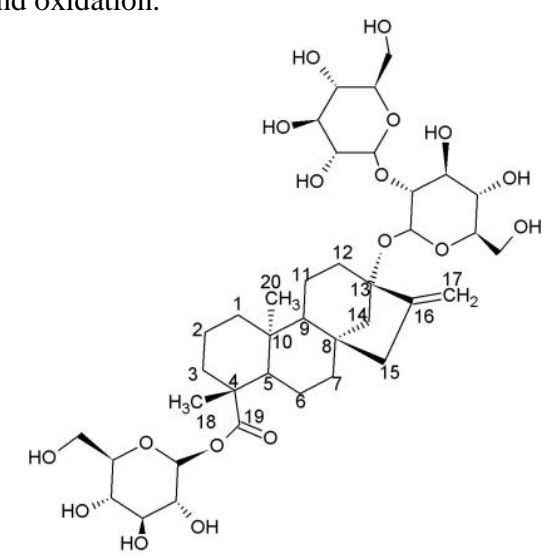

Fig. 1 Molecular structure of stevioside.

\section{EXPERIMENTAL}

\section{Materials}

A standard of stevioside used was purchased from WAKO, Japan that has purity grade of $99.0 \%$ based on Certificates of Analysis (CoA). 
Solvents for mobile phase of high performance liquid chromatography (HPLC) were acetonitrile (LC grade) and methanol (LC grade) Solvents for acid-base degradation were hydrochloric acid $(\mathrm{HCl})$, sulfate acid $\left(\mathrm{H}_{2} \mathrm{SO}_{4}\right)$, phosphoric acid $\left(\mathrm{H}_{3} \mathrm{PO}_{4}\right)$, and sodium hydroxide $(\mathrm{NaOH})$ (pro analysis grade). All these solvents were purchased from E. Merck, Germany. Oxidation agent used was hydrogen peroxide $\left(\mathrm{H}_{2} \mathrm{O}_{2}\right)$ (pro analysis grade), which was purchased from E. Merck, Germany.

\section{Forced Degradation of Stevioside}

\section{Acid-base Degradation}

Stevioside standard compound of $500 \mu \mathrm{g} / \mathrm{mL}$ was dissolved in distilled water, $\mathrm{HCl} 0.1 \mathrm{M}, \mathrm{NaOH} 0.1 \mathrm{M}, \mathrm{H}_{3} \mathrm{PO}_{4} 0.1 \mathrm{M}$, and citric acid $0.1 \mathrm{M}$. Each solution was heated using water bath at $80{ }^{\circ} \mathrm{C}$ for 8 hours. Each solution was cooled, neutralized and added to $10 \mathrm{~mL}$ of volume using water. Each solution was injected into HPLC system for degradation profile identification.

\section{Dry Heating Degradation}

A total of $2.5 \mathrm{mg}$ of stevioside was heated in an oven at $105{ }^{\circ} \mathrm{C}$ for 48 hours. Afterward, the stevioside degraded product was dissolved in 10 $\mathrm{mL}$ of distilled water prior to HPLC analysis.

\section{Ultraviolet (UV) Exposure Degradation}

Each of stevioside standard of $500 \mu \mathrm{g} / \mathrm{mL}$ dissolved in distilled water; $\mathrm{HCl} 0.1 \mathrm{M}$; and $\mathrm{NaOH} \mathrm{0.1} \mathrm{M.} \mathrm{Each} \mathrm{standard} \mathrm{solution} \mathrm{of} \mathrm{stevioside}$ was placed evenly forming a thin layer in a petri dish and closed. Each standard solution of stevioside was irradiated with a $\mathrm{UV}_{254 \mathrm{~nm}}$ lamp for 48 hours. Then, each standard solution of stevioside was removed and neutralized with trifluoroacetic acid (TFA) and triethylamine (TEA). Afterward, each standard solution of stevioside was fulfilled in volume up to $10 \mathrm{~mL}$ using water. Each solution was injected into HPLC system for degradation profile identification.

\section{Oxidation Degradation}

A total of stevioside of $250 \mu \mathrm{g} / \mathrm{mL}$ was dissolved in $\mathrm{H}_{2} \mathrm{O}_{2} 10 \%$ for 72 hours. The stevioside solution was placed at $25 \pm 5^{\circ} \mathrm{C}$ in dark for 72 hours for oxidative degradation.

\section{Reversed Phase-HPLC (RP-HPLC) Condition}

RP-HPLC conditions were adjusted according to the previous study (Martono et al., 2016). HPLC used was Knauer, GmBH, Germany. Stationary phase used was Eourosphere C-18 $(250 \times 4.6 \mathrm{~mm}, 5 \mu \mathrm{m})$ with a guard column. The mobile phase was a mixture of methanol $10 \%$ in water: acetonitrile $(65: 35, \mathrm{v} / \mathrm{v})$. TFA $0,01 \%(\mathrm{v} / \mathrm{v})$ was added into a mixture. The mobile phase was homogenized and degassed using an ultrasonic bath. A flow rate of mobile phase applied was 0.6 $\mathrm{mL} / \mathrm{min}$. Separation was detected using the UV detector at $210 \mathrm{~nm}$. Sample volume injected was $20 \mu \mathrm{l}$ using Rheodyne $7726 \mathrm{i}$ injector.

\section{Electrospray Ionization Tandem Mass Spectrometry (ESI- MS/MS)}

Stevioside standard and stably degraded hydrolysis of citric acid was injected directly (direct injection) in mass spectrometer system (Waters Xevo TQ-S) with electrospray ionization (ESI) method. Operational conditions used were a capillary voltage of $2.5 \mathrm{kV}$, cone voltage of $80 \mathrm{~V}$, a source voltage of $60 \mathrm{~V}$. Gas desolvation temperature was $450{ }^{\circ} \mathrm{C}$. Gas desolvation flow rate was $800 \mathrm{~L} / \mathrm{h}$, cone of $150 \mathrm{~L} / \mathrm{hr}$ and nebulizer of 7.0 bar pressure. The conditions of the analyzer were low mass (LM) resolution 1 and 2 was 3.00 and high mas (HM) resolution 1 and 2 was 15.00. Energy ion 1 was $1.0 \mathrm{~V}$ and ion 2 was $2.0 \mathrm{~V}$. Collision gas flow used was $15 \mathrm{~mL} / \mathrm{min}$. The $\mathrm{m} / \mathrm{z}$ values analyzed by ESI-MS were in the range of 50-1250 amu.

\section{RESULTS AND DISCUSSION}

\section{Stevioside degradation evaluation using RP-HPLC}

Stevioside stability is influenced by stressor applied to the compounds. Percentage of stevioside degradation was calculated based on the remaining stevioside peak area after treatments of degradation by the stressor. The result of this study demonstrated that stevioside was hydrolyzed in distilled water at $80{ }^{\circ} \mathrm{C}$ for 8 hours with degradation of $25 \%$, whereas at the same hydrolysis condition in 0.1 $\mathrm{M} \mathrm{NaOH}$ solution caused total degradation of the stevioside compounds. The stevioside compound was more stable to acid hydrolysis than in basic solutions, in which stevioside degradation of $\mathrm{HCl}$ hydrolysis reached $81 \%$ (Table 1 and Fig. 2). The results of this study were consistent with the results of reported studies (Musa et al., 2014; Wölwer-Rieck et al., 2010), which showed that the stevioside was more stable in the hydrolysis of distilled water.

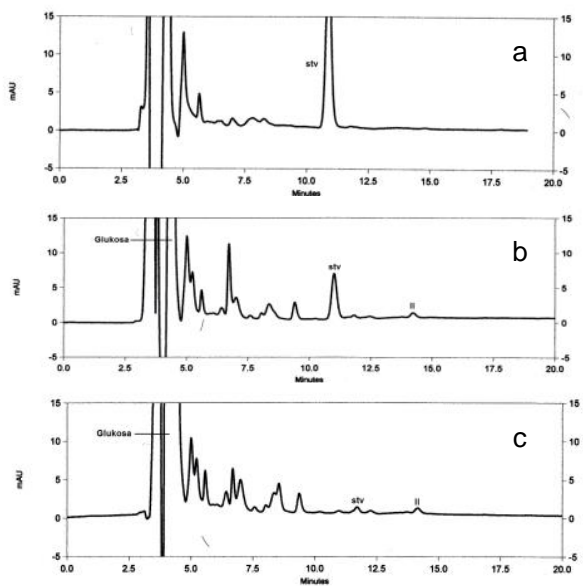

Fig. 2 RP-HPLC chromatograms of stevioside degradation in (a) distillated water, (b) $0.1 \mathrm{M} \mathrm{HCl}$, and (c) $0.1 \mathrm{M} \mathrm{NaOH}$ for 8 hours at 80 ${ }^{\circ} \mathrm{C}$. Stv $=$ stevioside.

As shown in Table 1, the stevioside compound was more degraded in phosphoric acid solution than in citric acid solution under hydrolysis conditions at $80{ }^{\circ} \mathrm{C}$ for 8 hours. Phosphoric acid degraded stevioside by $98 \%$, while citric acid degraded stevioside by $86 \%$ (Fig. 3 ). The results of this study were consistent with the results of research Kroyer (2010), suggesting that stevioside was more degraded in phosphoric acid.

Table 1 Degradation percentage of stevioside in several stressors.

\begin{tabular}{lcc}
\hline \multicolumn{1}{c}{ Stressor } & \multicolumn{2}{c}{ Stevioside } \\
\cline { 2 - 3 } & $\begin{array}{c}\text { Concentration } \\
(\mu \mathrm{g} / \mathrm{mL})\end{array}$ & $\begin{array}{c}\text { Percentage of } \\
\text { degradation } \\
(\%)\end{array}$ \\
\hline Standard & 134.20 & - \\
Distilled water hydrolysis & 121.85 & 25.86 \\
$0.1 \mathrm{M} \mathrm{HCl}$ hydrolysis & 31.26 & 80.98 \\
$0.1 \mathrm{NaOH}$ hydrolysis & n.q. & 100 \\
$0.1 \mathrm{M}$ citric acid hydrolysis & 22.24 & 86.47 \\
$0.1 \mathrm{M}$ phosphoric acid & 1.90 & 98.84 \\
hydrolysis & 14.87 & 90.96 \\
Dry heating & 76.42 & 53.51 \\
$\mathrm{UV}_{254}$ exposure in distilled & 74.90 & 54.43 \\
water $_{\mathrm{UV}_{254} \text { exposure in } 0.1 \mathrm{M} \mathrm{HCl}}$ & 14.65 & 91.09 \\
$\mathrm{UV}_{254}$ exposure in $0.1 \mathrm{M} \mathrm{NaOH}$ & n.q. & 100 \\
$\mathrm{H}_{2} \mathrm{O}_{2}$ oxidation & & \\
\hline
\end{tabular}

n.q. = not quantified

The results also showed that stevioside was unstable in dry heating at $105{ }^{\circ} \mathrm{C}$ for 48 hours. Stevioside degradation by dry heating was $91 \%$. Stevioside was fully degraded by oxidation (Fig. 4). Stevioside was more stable in distilled water and $\mathrm{HCl} 0.1 \mathrm{M}$ solutions 
than in $\mathrm{NaOH} 0.1 \mathrm{M}$ solution by $\mathrm{UV}_{254} \mathrm{~nm}$ exposure. Levels of stevioside degradation to $\mathrm{UV}_{254 \mathrm{~nm}}$ exposure in distilled water and $\mathrm{HCl}$ $0.1 \mathrm{M}$ solutions were $53.5 \%$ and $54.4 \%$ respectively, whereas in $\mathrm{NaOH} 0.1 \mathrm{M}$ solution was $91.1 \%$ (Table 1 and Fig. 5). Product degradations were varied among stressor factor. Each stressor factor has specific energy to breakdown molecular bond of interested compound. In addition, the type of acid and base solution used to dissolve also affected the stability of the stevioside. It reflected that the stevioside degradation was influenced by stressor and environment factors.
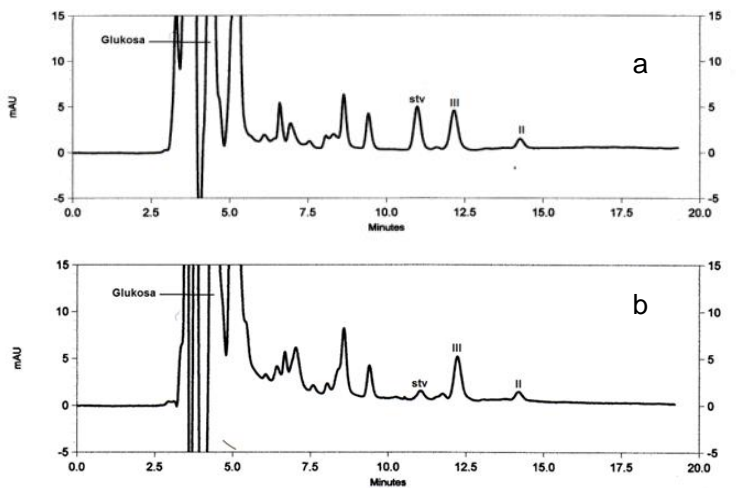

Fig. 3 RP-HPLC chromatograms of stevioside degradation in (a) $0.1 \mathrm{M}$ citric acid and (b) $0.1 \mathrm{M}$ phosporic acid for 8 hours at $80{ }^{\circ} \mathrm{C}$. Stv $=$ stevioside.
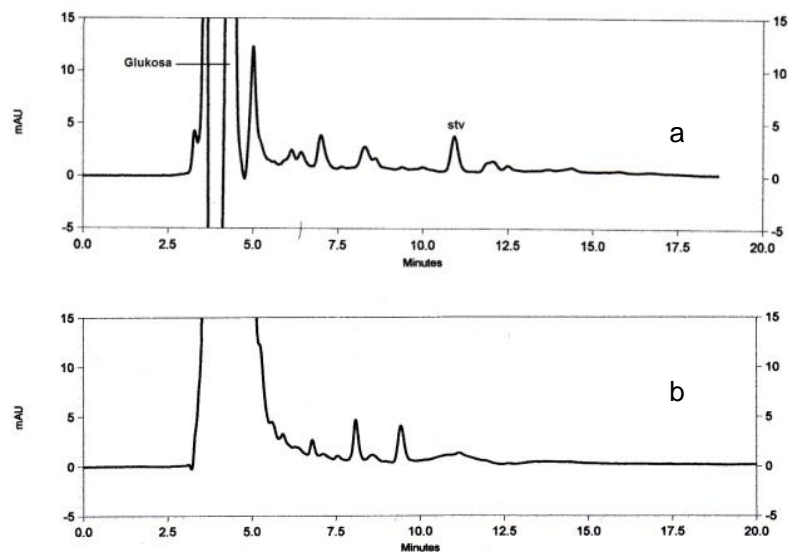

Fig. 4 RP-HPLC chromatograms of stevioside degradation in (a) dry heating of $105{ }^{\circ} \mathrm{C}$ for 48 hours and (b) oxidation by $\mathrm{H}_{2} \mathrm{O}_{2} \quad 10 \%$ for 72 hours. Stv $=$ stevioside.

\section{Identification of stevioside degradation product using ESI-} MS/MS

The identification of stevioside compound degradation product using ESI-MS/MS by direct inlet injection showed $\mathrm{m} / \mathrm{z}$ value as a basis for determining the possible structure of the degradation product. The residual stevioside compound was detected as $[\mathrm{MH}]^{-}$at $\mathrm{m} / \mathrm{z}=803$ (Fig. 6). Stevioside degradation causes glycoside bond termination. The $\mathrm{m} / \mathrm{z}$ value $[\mathrm{M}-162]^{-}$corresponded to the release of the sugar substituent (Musa et al., 2014). Stevioside lost one glucose molecule, resulting in a steviolbioside compound and was detected as $[\mathrm{MH}]^{-}$at $\mathrm{m} / \mathrm{z}=641$ (Fig. 7). One glucose molecule was terminated from steviolbioside compound and formed a steviolmonoside compound. Steviolmonoside was identified as $[\mathrm{MH}]^{-}$at $\mathrm{m} / \mathrm{z}=479$ (Fig. 8). Further analysis showed that the steviol compound was also formed from the degradation of stevioside and was detected as $[\mathrm{MH}]^{-}$ at $\mathrm{m} / \mathrm{z}=317$ (Fig. 9). The results of this study were consistent with the results of the reported studies (Catharino and Santos, 2012; Musa et al., 2014), which showed that stevioside would be degraded into various products by terminating glycoside bond and producing steviolbioside, steviolmonoside, and steviol.
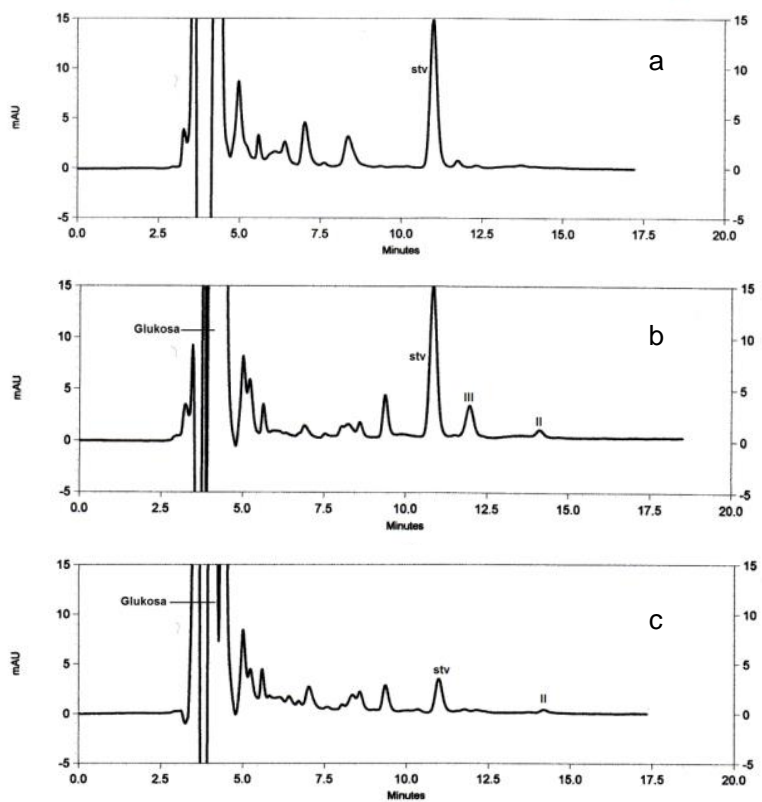

Fig. 5 RP-HPLC chromatograms of stevioside photodegradation in (a) distillated water; (b) $0.1 \mathrm{M} \mathrm{HCl}$; (c) $0.1 \mathrm{M} \mathrm{NaOH}$ by $\mathrm{UV}_{254 \mathrm{~nm}}$ exposure. Stv $=$ stevioside

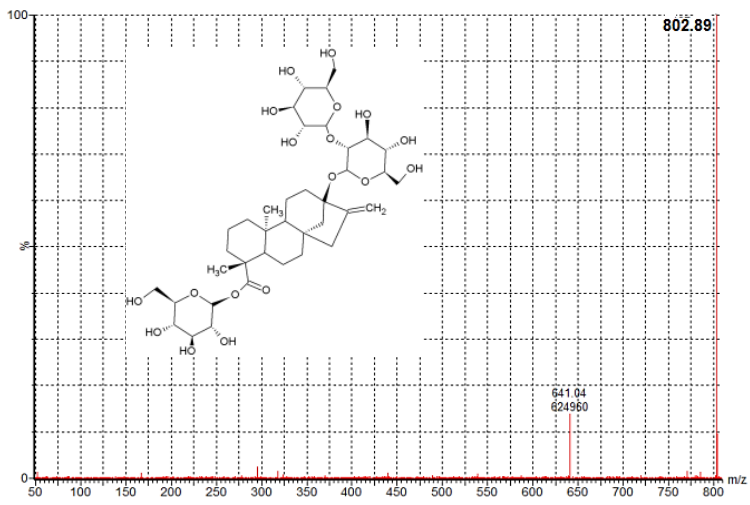

Fig. 6 Identification of stevioside $[\mathrm{M}-\mathrm{H}]^{-}(\mathrm{m} / \mathrm{z}=803)$ using ESI-MS/MS and its molecular structure.

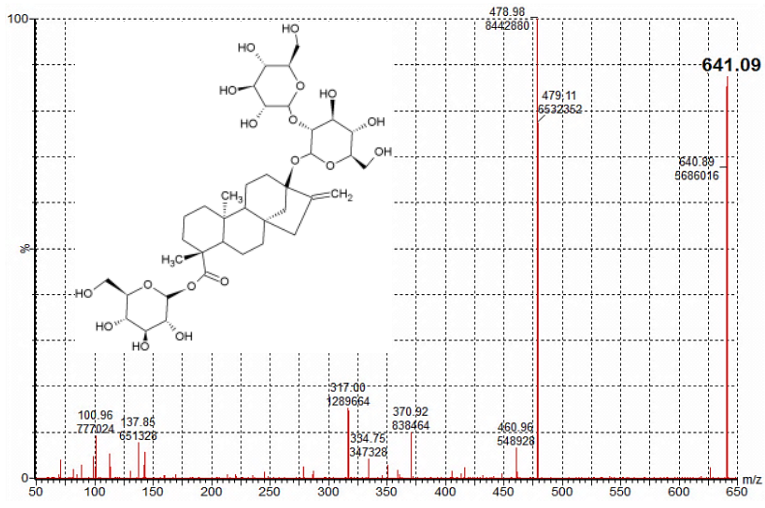

Fig. 7 Identification of steviolbioside $[\mathrm{M}-\mathrm{H}]^{-}(\mathrm{m} / \mathrm{z}=641)$ using ESI$\mathrm{MS} / \mathrm{MS}$ and its possible molecular structure. 


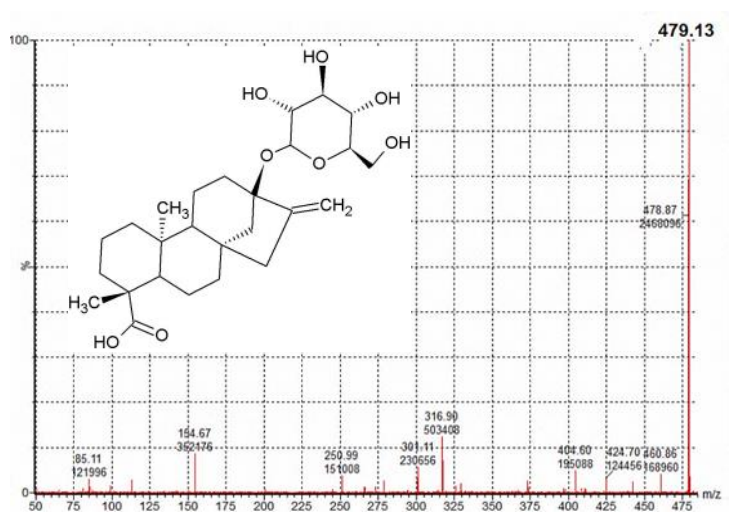

Fig. 8 Identification of steviolmonoside $[\mathrm{M}-\mathrm{H}]^{-}(\mathrm{m} / \mathrm{z}=479)$ using ESI$\mathrm{MS} / \mathrm{MS}$ and its possible molecular structure.

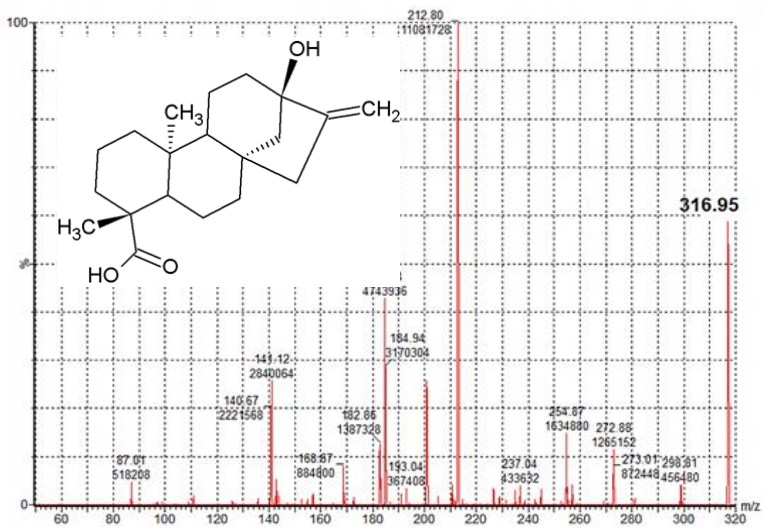

Fig. 9 Identification of steviol $[\mathrm{M}-\mathrm{H}]^{-}(\mathrm{m} / \mathrm{z}=317)$ using ESI-MS/MS and possible its molecular structure.

\section{CONCLUSION}

Stevioside degradation was influenced by acid-base hydrolysis, thermal, UV rays, and oxidation. The stevioside lost glucose molecule in degradation process and finally produced steviol. Pharmaceutical products containing stevioside were more stable in neutral solutions and shall be protected from UV exposure and possibly oxidation.

\section{ACKNOWLEDGEMENT}

This work was financially supported by Ministry of Research, Technology and Higher Education Indonesia and Universitas Kristen Satya Wacana Indonesia through Doctoral Dissertation Research Program 2016.

\section{REFERENCES}

Catharino, R. R., Santos, L. S. 2012. On-line monitoring of stevioside sweetener hydrolysis to steviol in acidic aqueous solutions. Food Chem., 133, 4, 1632-1635.

Chaturvedula, V. S. P., Prakash, I. 2011. Acid and alkaline hydrolysis studies of Stevioside and rebaudioside A. J. Appl. Pharm. Sci., 1, 8, 104-108.

Clos, J. F., DuBois, G. E., Prakash, I. 2008. Photostability of rebaudioside A and stevioside in beverages. J. Agric. Food Chem., 56, 8507-8513.

Gregersen, S., Jeppesen, P. B., Holst, J. J., Hermansen, K., 2004. Antihyperglycemic effects of stevioside in type 2 diabetic subjects. Metabolism, 53, 1, 73-76.

Hajihashemi, S., Geuns, J. M. C. 2013. Free radical scavenging activity of steviol glycosides, steviol glucuronide, hydroxytyrosol, metformin, aspirin and leaf extract of Stevia rebaudiana. Free Radic. Antioxid., 3, S34-S41.

Jeppesen, P. B., Gregersen, S., Poulsen, C. R., Hermansen, K. 2000. Stevioside acts directly on pancreatic $\beta$ cells to secrete insulin: Actions independent of cyclic adenosine monophosphate and adenosine triphosphate-sensitivie K+-channel activity. Metabolism, 49, 208-214.

Jooken, E., Amery, R., Struyf, T., Duquenne, B., Geuns, J., Meesschaert, B. 2012. Stability of steviol glycosides in several food matrices. J. Agric. Food Chem. 60, 10606-10612.

Kim, I.-S., Yang, M., Lee, O.-H., Kang, S.-N. 2011. The antioxidant activity and the bioactive compound content of stevia rebaudiana water extracts. LWT - Food Sci. Technol. 44, 1328-1332.

Kroyer, D. G. 2010. Stevioside and stevia-sweetener in food: application, stability, and interaction with food ingredients. J. Für Verbraucherschutz Leb. 5, 225-229.

Kujur, R. S., Singh, V., Ram, M., Yadava, H. N., Singh, K. K., Kumari, S., Roy, B. K. 2010. Antidiabetic activity and phytochemical screening of crude extract of stevia rebaudiana in alloxan-induced diabetic rats. Pharmacognosy Res., 2, 4, 258-263.

Martono, Y., Riyanto, S., Rohman, A., Martono, S. 2016. Improvement method of fast and isocratic RP-HPLC analysis of major diterpene glycoside from stevia rebaudiana leaves, AIP Conf. Proc. 1755, 080001.

Melis, M. S., Sainati, A. R. 1991. Effect of calcium and verapamil on renal function of rats during treatment with stevioside. J. Ethnopharmacol., 33, 257-262.

Musa, A., Miao, M., Gasmalla, M. A. A., Zhang, T., Eibaid, A., Aboshora, W., Jiang, B. 2014. Stability of stevioside and glucosyl-stevioside under acidic conditions and its degradation products. J. Food Nutr. Res. J. Food Nutr. Res., 2, 198-203.

Prakash, I., Clos, J. F., Chaturvedula, V. S. P. 2012. Stability of rebaudioside A under acidic conditions and its degradation products. Food Res. Int., 48, 6575.

Sehar, I., Kaul, A., Bani, S., Pal, H. C., Saxena, A. K. 2008. Immune up regulatory response of a non-caloric natural sweetener, stevioside. Chem. Biol. Interact. 173, 115-121.

Takasaki, M., Konoshima, T., Kozuka, M., Tokuda, H., Takayasu, J., Nishino, H., Miyakoshi, M., Mizutani, K., Lee, K.-H. 2009. Cancer preventive agents. Part 8: Chemopreventive effects of stevioside and related compounds. Bioorg. Med. Chem., 17, 600-605.

Tamizi, E., Jouyban, A. 2016. Forced degradation studies of biopharmaceuticals: Selection of stress conditions. Eur. J. Pharm. Biopharm. 98, 26-46.

Wang, L. S., Shi, Z., Shi, B. M., Shan, A. S. 2014. Effects of dietary stevioside/rebaudioside A on the growth performance and diarrhea incidence of weaned piglets. Anim. Feed Sci. Technol. 187, 104-109.

Wölwer-Rieck, U., Tomberg, W., Wawrzun, A., 2010. Investigations on the stability of stevioside and rebaudioside A in soft drinks. J. Agric. Food Chem., 58, 12216-12220. 